\title{
Country- and individual-level socioeconomic determinants of depression: multilevel cross-national comparison
}

\author{
Dheeraj Rai, ${ }^{*}$ Pedro Zitko, ${ }^{*}$ Kelvyn Jones, John Lynch and Ricardo Araya
}

\section{Background}

The prevalence and correlates of depression vary across countries. Contextual factors such as country-level income or income inequalities have been hypothesised to contribute to these differences.

\section{Aims}

To investigate associations of depression with socioeconomic factors at the country level (income inequality, gross national income) and individual (education, employment, assets and spending) level, and to investigate their relative contribution in explaining the cross-national variation in the prevalence of depression.

\section{Method}

Multilevel study using interview data of 187496 individuals from 53 countries participating in the World Health Organization World Health Surveys.

\section{Results}

Depression prevalence varied between 0.4 and $15.7 \%$ across countries. Individual-level factors were responsible for $86.5 \%$ of this variance but there was also reasonable variation at the country level (13.5\%), which appeared to increase with decreasing economic development of countries. Gross national income or country-level income inequality had no association with depression. At the individual level, fewer material assets, lower education, female gender, economic inactivity and being divorced or widowed were associated with increased odds of depression. Greater household spending, unlike material assets, was associated with increasing odds of depression (adjusted analysis).

\section{Conclusions}

The variance of depression prevalence attributable to country-level factors seemed to increase with decreasing economic development of countries. However, country-level income inequality or gross national income explained little of this variation, and individual-level factors appeared more important than contextual factors as determinants of depression. The divergent relationship of assets and spending with depression emphasise that different socioeconomic measures are not interchangeable in their associations with depression.

\section{Declaration of interest}

None.
Depression is a leading cause of morbidity and disability worldwide. ${ }^{1,2}$ The prevalence of depression varies across countries, ${ }^{3-6}$ even when estimated using comparable methods. Both country(contextual) and individual-level factors may contribute to this variation but the extent to which they influence this variability has not been adequately examined. At the country level, it has been suggested that income inequality may directly predispose individuals to poorer mental health, ${ }^{7}$ but the supporting evidence is limited and inconsistent. ${ }^{7-14}$ At the individual level, different socioeconomic measures have yielded varying relationships with depression. ${ }^{3,15,16}$ Due to a relative lack of studies from low- and middle-income countries, findings from richer countries are often extrapolated to other parts of the world. Such generalisations may be misleading, particularly if the determinants of depression vary across different regions of the world. Cross-national studies using comparable methods are therefore essential for a better understanding of the contextual and individual correlates of depression. Using data from representative samples from 53 countries participating in the World Health Organization (WHO) World Health Surveys (WHS), we aimed to: (a) estimate variations in the prevalence of depression across countries, (b) quantify the relative importance of contextual- and individuallevel factors in this variation, and (c) study the relationship between specific contextual (income inequalities and absolute income) and individual (spending, assets, education and occupation) socioeconomic characteristics with depression.

*These authors contributed equally to this work.

\section{Method}

\section{The World Health Surveys}

The WHS were carried out by the WHO in 2002-2003 in countries sampled to represent all regions of the world. ${ }^{1,17,18}$ The aim of the surveys was to allow worldwide comparisons of health outcomes using valid, reliable and comparable methods. The survey tools and questionnaires were developed by WHO and piloted in 12 countries before the main surveys. ${ }^{18}$ The WHS team undertook intensive consultation with participating countries, international experts and regional advisors to ensure high-quality surveys in accordance with explicit operational criteria and quality standards in the WHS Quality Assurance Standards and Guidelines. ${ }^{18}$ Standardised WHO protocols were used to translate the survey instruments into local languages, which included back translation. The WHO regional centres organised training courses for participating countries. Survey teams in individual countries implemented the sampling and the survey. Sample sizes between 1000 and 10000 were recommended but this varied in individual countries according to feasibility and needs. In each participating country, a stratified random, probabilistic sampling design was used, and samples were representative of the population $\geqslant 18$ years, including people in institutions. ${ }^{18}$ The surveys were completed in 70 countries (online Table DS1). A multistage cluster design was used in all countries except Australia, China, Comoros, Congo, Cote d'Ivorie, Croatia, India and Russia. Face-to-face interviews (in Luxembourg and Israel the mode of administration was by telephone interviews) 
were conducted after informed consent from participants. The individual response rates, representing the ratio of completed interviews in selected respondents, excluding ineligible respondents from the denominator, ranged between $63 \%$ in Israel and $99 \%$ in the Philippines, ${ }^{1}$ and is estimated to be $98.5 \%$ for the surveys as a whole. ${ }^{17}$ We used data from 53 countries that had information on all key variables of interest (see Table DS1 for reasons for exclusion). These comprised 16 low-income, 13 middle-lowerincome, 12 middle-upper-income and 12 high-income countries according to World Bank criteria (Fig. 1). Detailed information about the WHS, including the survey tools, sampling guidelines and procedures, and country by country statistics, is available elsewhere (www.who.int/healthinfo/survey/en/).

\section{Assessment of depression}

Questions based on the WHO World Mental Health Survey version of the Composite International Diagnostic Interview were administered, ${ }^{19}$ and validated algorithms used to derive a diagnosis of a depressive episode based on the ICD-10. ${ }^{20}$ The presence of four depressive symptoms lasting 2 weeks for most or all of the day was required for a diagnosis of a depressive episode. At least two of three core symptoms - depressed mood, loss of interest and fatigability - needed to be present. Other symptoms included loss of appetite and slowing down in thinking.

\section{Contextual (country-level) measures}

\section{Gross national income}

We used data from the World Bank (http://data.worldbank.org/ indicator) to compile the 2002 gross national income (GNI) per capita for each country in US\$, adjusted according to purchasing power parity (PPP). Purchasing power parity is a rate of exchange that accounts for price differences across countries allowing international comparisons. The GNI measures the total value produced in the country, plus income from other sources, less similar payments made to other countries. ${ }^{21}$ In our data, this varied from US\$500 in Ethiopia to US\$47730 in Luxembourg. We log-transformed this variable for analysis in an attempt to linearise its relationship with depression. ${ }^{22}$

\section{Income inequality}

We used the GINI index, the most widely used measure of country-level income inequality, which reflects the extent to which the distribution of income among individuals or households within a country deviates from a perfect distribution. We obtained the GINI index values for each country closest to the year 2002 from the World Bank website (http://data.worldbank.org/ indicator), except for Mauritius for which we obtained data from the World Inequalities Database (www.wider.unu.edu/research/ Database/en_GB/database); GINI coefficients were expressed on the percentile scale $(0$ representing total equality and 100 representing maximal inequality). In the data these ranged from 25.00 in Sweden to 74.33 in Namibia.

\section{Individual-level measures}

\section{Household spending}

Participants were asked to estimate their total household expenditure in the previous month in local currency. This was followed by questions related to expenditure in specific areas including food, housing and healthcare, among other expenditure. A previous analysis of the WHS has shown the aggregate of the expenditures reported in these areas to be consistent with the total reported household expenditure. ${ }^{23}$ We divided the total monthly household expenditure by the number of individuals in the household to calculate monthly per-capita household spending. For analysis, we divided individuals into quintiles of household spending for each country, eliminating the need to transform the local currency into an internationally comparable currency such as US\$ adjusted for PPP.

\section{Material assets index}

We derived this index using responses regarding ownership of any of nine assets in the household (television, washing machine, dishwasher, mobile telephone, fixed telephone, computer, refrigerator, bicycle and car) and the level of household crowding (number of residents/room). We calculated probabilities of a household having each of the above assets and the mean level of crowding for each specific country. The material assets index reflects a country-specific standardised score for each household, reflecting the sum of the complements of the probability of having each asset and mean level of household crowding in the context of the country.

We were therefore able to differentiate between material assets and spending, variables that have been combined in previous studies to create indexes of permanent income. ${ }^{1,17,24}$

\section{Education}

We used the reported number of years of completed education as a categorical variable representing $<8,8-12$ and $>12$ years of education.

\section{Occupation}

We coded respondents into three categories: higher-level professionals/managers, other manual and non-manual workers, and those not working for pay.

\section{Other demographic variables}

These included age, gender and marital status (currently married or cohabiting, separated or divorced, never married and widowed) and area of residence (urban or rural).

\section{Analysis}

We first estimated the weighted prevalence of depression in each country, taking into account the sampling design. We drew forest plots to visually examine the variation in prevalence of depression across countries. We also calculated summary estimates of the prevalence of depression for countries grouped according to levels of economic development (low income, middle-lower income, middle-upper income and high income, available at: http://data. worldbank.org/about/country-classifications/country-and-lendinggroups). We then used multilevel methods to assess the proportion of the variance in the prevalence of depression attributable to country- and individual-level factors using MLWin 2.24 (Centre for Multilevel Modelling, University of Bristol, Bristol, UK, www.bris.ac.uk/cmm/software/mlwin/) on Windows. We obtained variance partitioning coefficients (VPC) using the "latent variable method', in which the individual's risk of depression follows a logistic distribution, with individual-level variance equal to 3.29. ${ }^{25,26}$ Variance partitioning coefficients quantify the amount of country-level variance over the total model variance. We also calculated median odds ratios (MORs) defined as 'the median value of the odds ratio between the country at highest risk and the country at lowest risk when randomly picking out two countries' with their $95 \%$ confidence intervals. ${ }^{26}$ The MOR represents the median increase in risk of depression if an 
individual moved to another country with a higher risk. ${ }^{26}$ Both VPCs and MORs help to understand the importance of country-level factors, but the VPCs may vary depending on the prevalence of the outcome. The VPCs and MORs were calculated for: (a) empty multilevel model; (b) multilevel model adjusted for individual-level variables (i.e. age, gender, marital status, area type, household spending, assets index, education and occupation); and (c) separate crude and adjusted (for individual-level variables) multilevel models with country-level variables (GINI index and GNI).

To study the determinants of depression, we calculated odds ratios (ORs) and 95\% confidence intervals through two-level logistic regression models in MLWin using restricted iterative generalised least squares (RIGLS) estimation with predictive quasi-likelihood (PQL) 2nd order Taylor series expansion. ${ }^{27} \mathrm{We}$ adjusted for all the individual- and country-level variables to arrive at our final model.

To investigate whether associations followed similar patterns in countries with different economic development, we repeated all analyses after grouping the countries into high-, upper-middle-, lower-middle-, and low-income countries.

Finally, we tested for cross-level interactions to assess variations by country-level income (GNI) and income inequality (GINI index) in the relations between depression and individual characteristics by including multiplicative interaction terms in the regression models.

For all main analysis presented here, the sample included individuals with complete data on all the variables. We repeated the analysis on larger data-sets, including all available data to check for the possibility of any biases due to missing data. Since weighted analyses for discrete response models in MLWin are considered experimental, we did not use weights for the multilevel models. In sensitivity analysis we (a) compared the prevalence estimates of depression with and without weights; (b) repeated the regression estimations including the countries without probability weights, raising the database to 61 countries; and (c) repeated the analyses using available weights, but instead of using the random effect of countries in the intercept, we included dummy variables for each country. In these analyses we also compared the results excluding countries in which the prevalence of depression could be considered as an outlier.

\section{Results}

Complete data were available for 187496 individuals residing in 53 countries.

\section{Variation in the prevalence of depression across the countries}

The prevalence of depression ranged from $0.4 \%$ in Vietnam to $15.7 \%$ in Morocco. However, the mean estimates of depression prevalence for countries grouped according to economic development were similar, ranging from $6.0 \%$ in low-income countries to $7.6 \%$ in upper-middle-income countries, with some possible outliers in each group (Fig. 1).

The empty model on the pooled sample found that $13.5 \%$ $(\mathrm{MOR}=1.98)$ of the total variance in the prevalence of depression was explained at the country level and over $85 \%$ at the individual level (Table 1). These estimates did not change when the individual-level variables were added to the model. When countries were grouped according to economic development, the results showed that the percentage of variance explained at country level increased progressively as level of economic development decreased (from $5.5 \%$ in high-income to $22.4 \%$ in low-income countries, Table 1). However, the confidence intervals of the MORs reflecting this finding overlapped.

\section{Determinants of depression}

\section{Country-level absolute income (GNI) and income inequality (GINI index)}

There were no associations of depression with country-level absolute income (adjusted OR $=1.10$, 95\% CI 0.93-1.30) or income inequality $(\mathrm{OR}=1.00,95 \%$ CI $0.98-1.02)$. These results were consistent across all groups of countries, including high-income countries. (Table 2).

\section{Individual-level variables}

Among demographic variables, female gender, being divorced or widowed were associated with higher odds of depression in the pooled sample. Individuals with less than 8 years of education $(\mathrm{OR}=1.52,95 \%$ CI 1.40-1.64) were more likely, and those with a higher material assets index $(\mathrm{OR}=0.87,95 \%$ CI $0.85-0.89)$ less likely to be depressed. The household per-capita spending was not associated with depression in the crude model, but in adjusted models individuals reporting higher spending were more likely to be depressed. People not working for pay also had higher odds of depression (Table 3).

Results of repeating analyses in countries grouped by economic development are presented in Table 4. The associations between age, female gender and marital status with depression were robust across country groups. Noticeably the relationship between female gender and depression became stronger with increasing economic development of countries. A lower education had an association of a similar magnitude with depression across high-, middle- and low-income countries. A higher material assets index was inversely associated with depression, but the strength of the associations differed between country groups in a non-linear pattern. The direct association of increasing per-capita household spending with depression was also observed in all country groups. Finally, economically inactive people showed higher odds of depression in all country groups except low-income countries.

\section{Cross-level interactions}

We did not find evidence of interactions at the 5\% significance level between contextual- and individual-level variables except a significant cross-level interaction $(P<0.001)$ between the GNI of countries and gender (Fig. 2). In women, the prevalence of depression across countries increased almost twofold with increasing GNI, whereas this remained constant in men.

\section{Sensitivity analysis}

In sensitivity analyses we removed three countries (Morocco, Portugal and Brazil) that had a much higher prevalence of depression, and three countries (China, Vietnam and Laos) that had a much lower prevalence of depression than countries in their respective groups (Fig. 1), and this led to no significant changes in the regional estimates of depression. The removal of countries with the lowest prevalence estimates of depression led to, as expected, some attenuation in the variability of depression at the country level (the country-level VPC dropped from 13.5 to $9.2 \%$ ), although the trends observed were largely similar and the associations of depression with both contextual and individual determinants of depression were essentially unaltered. We also repeated the analyses including the countries with missing probability weights, raising the database to 61 countries. Results 
(a)

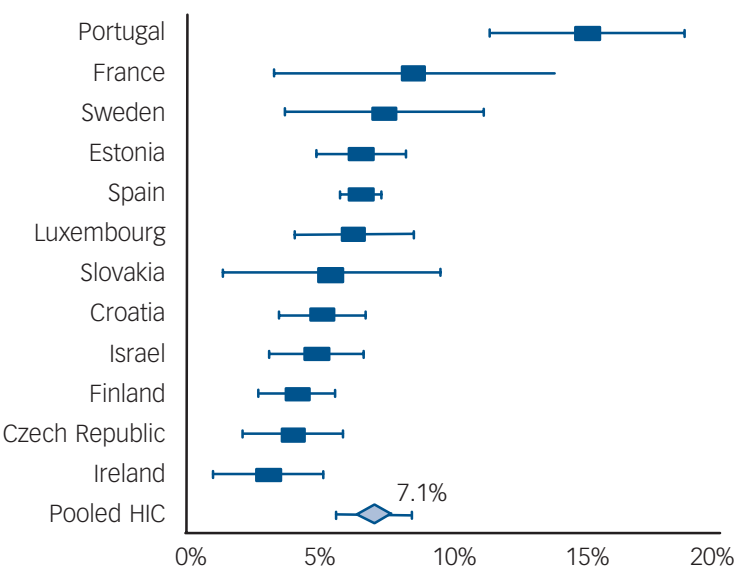

(c)

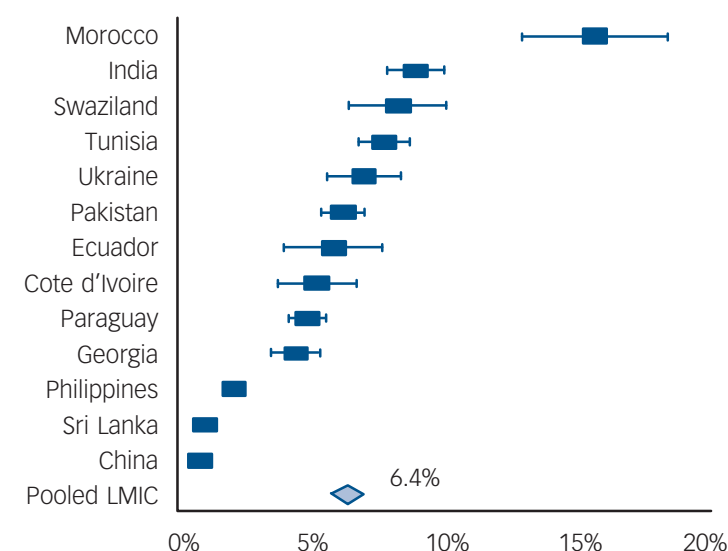

(b)

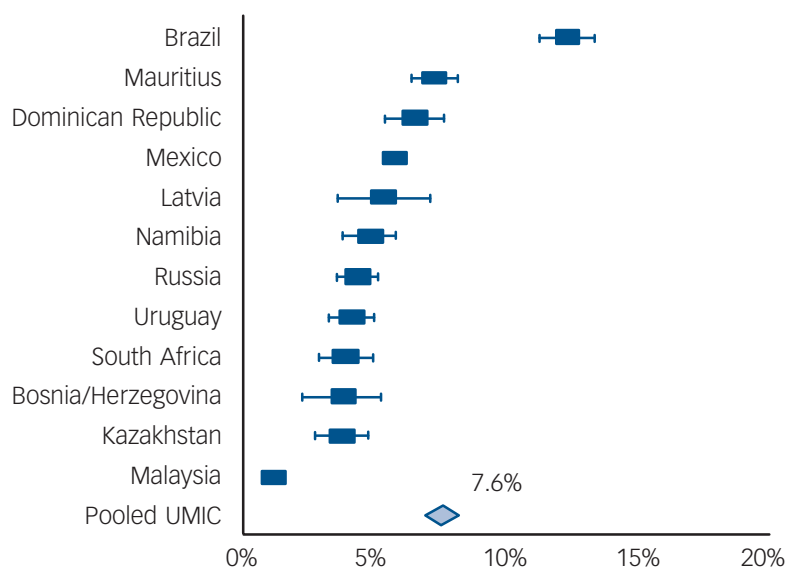

(d)

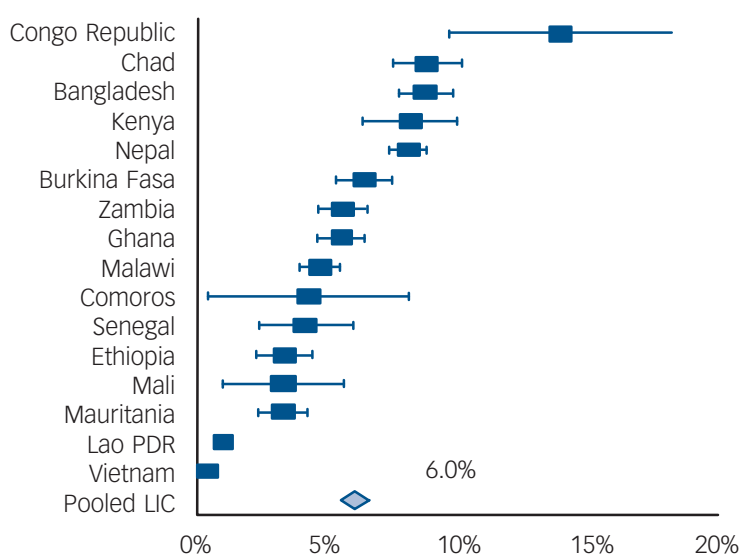

Fig. 1 Estimated country-level prevalence of depression grouped by economic development of countries (World Bank Criteria).

PDR, People's Democratic Republic.

(a) High-income countries (HIC); (b) Upper-middle-income countries (UMIC); (c) lower-middle-income countries (LMIC); (d) low-income countries (LIC).

remained almost identical, but we observed a weak but marginally significant relationship between income inequality and depression in high-income countries $(\mathrm{OR}=1.04,95 \%$ CI $1.00-1.09$, online Table DS2). This relationship lost conventional statistical significance on exclusion of Portugal, an outlier with an unusually high prevalence of depression $(\mathrm{OR}=1.03,95 \% \mathrm{CI}$ 0.98-1.07). All other results remained largely unaltered including the prevalence estimates (Table DS1) and determinants of depression in other sensitivity analyses.

\section{Discussion}

In this large, multilevel study of 187496 individuals from 53 countries, the prevalence of depression varied substantially, ranging from 0.4 to $15.7 \%$. Individual-level factors explained most of this variance, but there was also a reasonable amount of variation in the prevalence of depression at the country level (13.5\%). Interestingly, the importance of contextual (countrylevel) factors appeared to increase with decreasing economic development of countries, although the statistical significance of this trend could not be established. We found little evidence to suggest that country-level income inequality or GNI were important determinants of depression. At the individual level, female gender, being separated, divorced or widowed, fewer years of education or material assets were important determinants of depression. The prevalence of depression in women increased with rising GNI of countries, whereas this remained constant in men.

\section{Depression prevalence: relative contribution of contextual and individual factors}

Previous cross-national comparisons have also found marked differences in prevalence of depression across countries. ${ }^{3,4,6,28}$ Some authors suggest that these findings may be explained by varying thresholds of clinically relevant symptoms in different cultural contexts. ${ }^{4}$ However, systematic attempts to test this theory have not found it to be an adequate explanation. ${ }^{3}$ Another plausible explanation is that there are differences in how people respond to questions related to mental health. This was highlighted in two mental health surveys in China, which found contrasting results using different instruments and data-collection methods. ${ }^{5,29}$ It is also possible that these results may represent true differences in the prevalence of depression across countries.

We quantified the relative contribution of contextual(country) and individual-level factors in explaining this variation, and found that most of it could be attributed to individual-level factors. However, country-level factors also played a noticeable role, with their importance appearing to be increasing with decreasing economic development of countries. Considering the number of countries in each group were relatively few, the relatively wide and overlapping confidence intervals of the corresponding MORs may reflect insufficient statistical power and the statistical significance of this trend could not be established. Nevertheless, the proportion of variance attributable to the country level is noteworthy because previous within-country studies have found that higher level factors such 


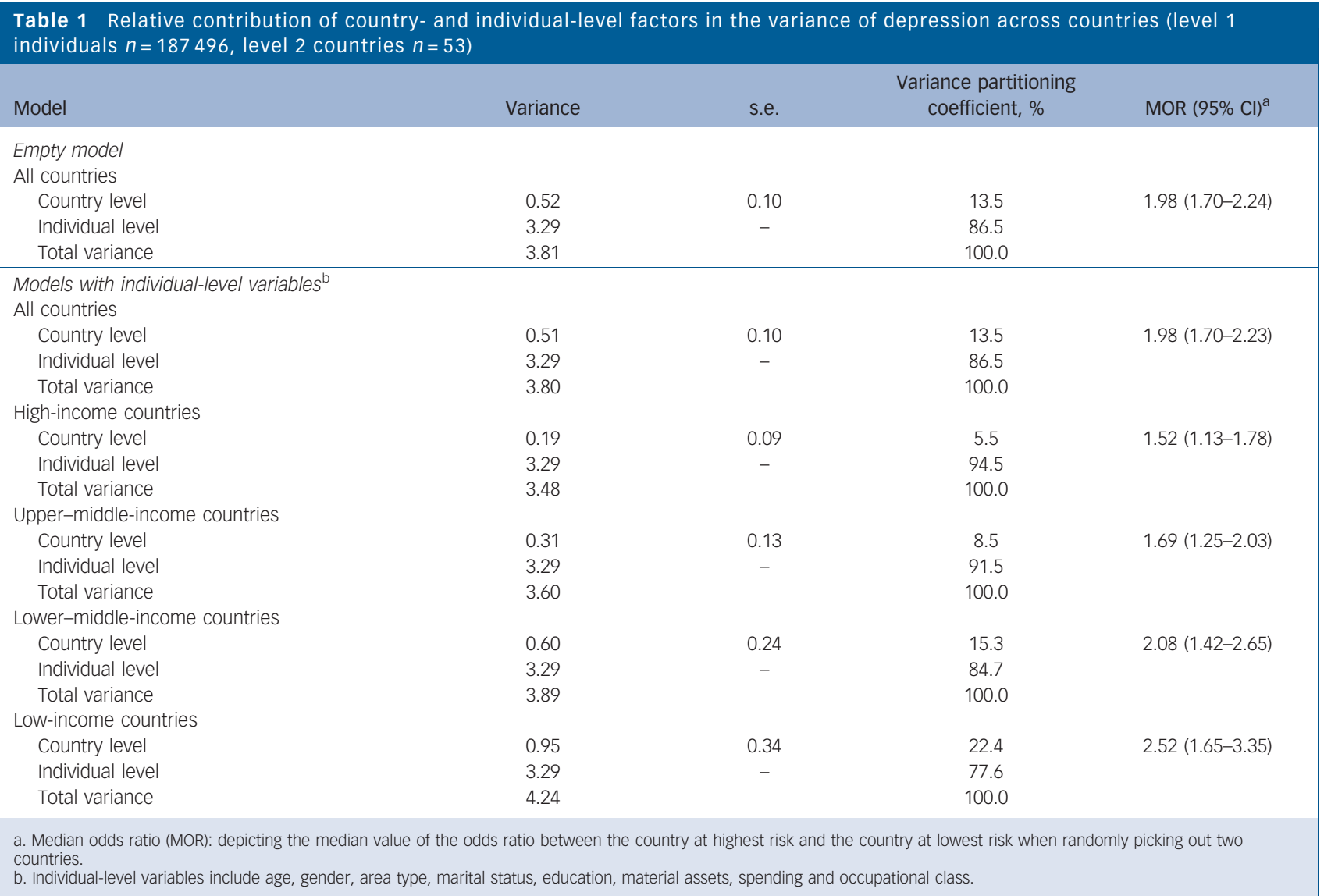

as neighbourhoods or areas of residence explain less than $5 \%$ of such variance. ${ }^{13,30-32}$

\section{Country-level income inequality and depression}

We found no evidence suggesting that income inequality is a major determinant of depression (Table 2). The proponents of the "income inequalities hypothesis" ${ }^{\text {'7 }}$ have published three analyses plotting the prevalence of psychiatric morbidity against country-level inequality measures in some high-income countries (with overlapping data), and reported significant correlations of psychiatric morbidity with income inequality. ${ }^{7,11,33}$ The absence of individual-level data in these studies makes the results liable to imprecision and a wide variety of interpretations. ${ }^{34}$ Since the authors have argued that ecological designs are appropriate for the study of inequality, we attempted to replicate their methodology (Fig. 3) but found no meaningful associations between income inequalities and depression. In our sensitivity analysis on the 61-country sample, there was weak evidence of a relationship between income inequality and depression in high-income countries, but this estimate was attenuated after removal of just one country, Portugal, an outlier within this group. This highlights how sensitive estimates from ecological studies can be to the inclusion or exclusion of countries from the analysis, an important issue that has also been illustrated by studies testing the relationship between income inequalities and other outcomes. $^{22,35}$

Another study using the WHS data found no evidence of a relationship between country-level income inequality and

\section{Table 2 The association between country-level absolute income and income inequality and depression: multilevel logistic} regression analysis ${ }^{\mathrm{a}}$

\begin{tabular}{|c|c|c|}
\hline \multicolumn{3}{|l|}{ Gross national income (logGNI) } \\
\hline All countries $(n=53)$ & $1.07(0.91-1.26)$ & $1.10(0.93-1.30)$ \\
\hline High-income countries & $1.11(0.54-2.27)$ & $1.51(0.79-2.87)$ \\
\hline Upper-middle-income countries & $0.87(0.20-3.84)$ & $0.89(0.23-3.40)$ \\
\hline Lower-middle-income countries & $1.10(0.36-3.43)$ & $1.06(0.33-3.43)$ \\
\hline Low-income countries & $1.60(0.69-3.69)$ & $0.91(0.24-3.39)$ \\
\hline \multicolumn{3}{|l|}{ Income inequality (GINI index) } \\
\hline All countries $(n=53)$ & $1.00(0.98-1.02)$ & $1.00(0.98-1.02)$ \\
\hline High-income countries & $1.04(0.99-1.10)$ & $1.03(0.97-1.08)$ \\
\hline Upper-middle-income countries & $1.01(0.98-1.04)$ & $1.01(0.98-1.03)$ \\
\hline Lower-middle-income countries & $0.99(0.94-1.03)$ & $0.99(0.94-1.03)$ \\
\hline Low-income countries & $1.03(0.98-1.08)$ & $1.03(0.96-1.10)$ \\
\hline
\end{tabular}




\begin{tabular}{|c|c|c|}
\hline & Crude OR $(95 \% \mathrm{Cl})$ & Adjusted $\mathrm{OR}^{\mathrm{a}}(95 \% \mathrm{Cl})$ \\
\hline Age, years & $1.02(1.02-1.02)$ & $1.01(1.01-1.02)$ \\
\hline Female (male reference) & $1.88(1.81-1.96)$ & $1.64(1.52-1.72)$ \\
\hline Rural area type (urban reference) & $1.07(1.02-1.11)$ & $0.95(0.90-0.99)$ \\
\hline \multicolumn{3}{|l|}{ Marital status } \\
\hline Currently married or cohabiting & $1.00(-)$ & $1.00(-)$ \\
\hline Separated or divorced & $1.86(1.73-2.00)$ & $1.64(1.52-1.77)$ \\
\hline Never married & $0.75(0.71-0.79)$ & $1.01(0.95-1.08)$ \\
\hline Widowed & $2.52(2.38-2.66)$ & $1.42(1.33-1.51)$ \\
\hline \multicolumn{3}{|l|}{ Education } \\
\hline More than 12 years & $1.00(-)$ & $1.00(-)$ \\
\hline $8-12$ years & $1.22(1.13-1.32)$ & $1.09(1.01-1.19)$ \\
\hline Less than 8 years & $2.29(2.14-2.45)$ & $1.52(1.40-1.64)$ \\
\hline Material assets index & $0.82(0.80-0.84)$ & $0.87(0.85-0.89)$ \\
\hline \multicolumn{3}{|l|}{ Spending } \\
\hline Quintile 5 (lowest) & $1.00(-)$ & $1.00(-)$ \\
\hline Quintile 4 & $0.99(0.93-1.06)$ & $1.02(0.95-1.09)$ \\
\hline Quintile 3 & $1.00(0.94-1.07)$ & $1.05(0.98-1.12)$ \\
\hline Quintile 2 & $1.05(0.98-1.11)$ & $1.14(1.06-1.21)$ \\
\hline Quintile 1 (highest) & $1.03(0.97-1.09)$ & $1.24(1.16-1.33)$ \\
\hline \multicolumn{3}{|l|}{ Occupational class } \\
\hline High professionals & $1.00(-)$ & $1.00(-)$ \\
\hline Other non-manual and manual workers & $1.39(1.25-1.55)$ & $1.11(0.99-1.24)$ \\
\hline Not working for pay & $2.29(2.06-2.55)$ & $1.33(1.18-1.49)$ \\
\hline
\end{tabular}

depression in the overall sample. ${ }^{14}$ However, the authors reported a significant association between income inequality and depression in countries with a high human development index (HDI), recommending policy changes to address the impact of inequality on depression. More caution may be warranted for a number of reasons. First, the 'significant' association reported was marginal (OR $=1.04,95 \% \mathrm{CI} 1.00-1.08)$ and, as we found, was lost on removal of a single country (Portugal) from the analysis. Second, the authors adjusted their results only for education, an important but not the only potential socioeconomic confounder of this association. Finally, the authors used the HDI, a composite indicator of development that has been criticised for

Table 4 Individual-level socioeconomic correlates of depression: multilevel logistic regression analysis of sample by economic development of countries ${ }^{a}$

\begin{tabular}{|c|c|c|c|c|}
\hline & \multicolumn{4}{|c|}{ Adjusted $\mathrm{OR}^{\mathrm{a}}(95 \% \mathrm{Cl})$} \\
\hline & $\begin{array}{l}\text { High-income } \\
\text { countries }\end{array}$ & $\begin{array}{l}\text { Upper-middle-income } \\
\text { countries }\end{array}$ & $\begin{array}{l}\text { Lower-middle-income } \\
\text { countries }\end{array}$ & $\begin{array}{l}\text { Low-income } \\
\text { countries }\end{array}$ \\
\hline Age, years & $1.00(0.99-1.00)$ & $1.01(1.01-1.01)$ & $1.02(1.01-1.02)$ & $1.02(1.01-1.02)$ \\
\hline Female & $2.10(1.80-2.47)$ & $1.81(1.67-1.95)$ & $1.45(1.32-1.60)$ & $1.42(1.30-1.55)$ \\
\hline Rural area (urban reference) & $1.01(0.87-1.18)$ & $0.92(0.86-1.00)$ & $0.87(0.79-0.95)$ & $1.03(0.94-1.14)$ \\
\hline \multicolumn{5}{|l|}{ Marital status } \\
\hline Married or cohabiting & $1.00(-)$ & $1.00(-)$ & $1.00(-)$ & $1.00(-)$ \\
\hline Separated or divorced & $1.42(1.12-1.81)$ & $1.71(1.54-1.91)$ & $1.81(1.49-2.21)$ & $1.53(1.31-1.80)$ \\
\hline Never married & $1.00(0.81-1.23)$ & $1.10(0.99-1.21)$ & $0.94(0.84-1.06)$ & $0.95(0.82-1.09)$ \\
\hline Widowed & $1.31(1.08-1.60)$ & $1.38(1.25-1.53)$ & $1.40(1.23-1.60)$ & $1.63(1.44-1.85)$ \\
\hline \multicolumn{5}{|l|}{ Education } \\
\hline More than 12 years & $1.00(-)$ & $1.00(-)$ & $1.00(-)$ & $1.00(-)$ \\
\hline $8-12$ years & $1.17(0.96-1.44)$ & $1.07(0.94-1.21)$ & $1.15(0.99-1.35)$ & $1.66(1.33-2.07)$ \\
\hline Less than 8 years & $1.58(1.27-1.97)$ & $1.64(1.44-1.86)$ & $1.44(1.24-1.68)$ & $1.63(1.44-1.85)$ \\
\hline Material assets index & $0.82(0.76-0.89)$ & $0.92(0.89-0.96)$ & $0.78(0.74-0.82)$ & $0.88(0.83-0.92)$ \\
\hline \multicolumn{5}{|l|}{ Spending } \\
\hline Quintile 5 (lowest) & $1.00(-)$ & $1.00(-)$ & $1.00(-)$ & $1.00(-)$ \\
\hline Quintile 4 & $1.20(0.95-1.53)$ & $1.16(1.05-1.28)$ & $0.80(0.70-0.92)$ & $0.99(0.87-1.13)$ \\
\hline Quintile 3 & $1.29(1.03-1.63)$ & $1.10(0.99-1.22)$ & $0.85(0.74-0.97)$ & $1.12(0.99-1.27)$ \\
\hline Quintile 2 & $1.32(1.06-1.66)$ & $1.17(1.05-1.30)$ & $1.04(0.92-1.18)$ & $1.18(1.04-1.34)$ \\
\hline Quintile 1 (highest) & $1.40(1.12-1.76)$ & $1.24(1.11-1.38)$ & $1.32(1.15-1.50)$ & $1.24(1.09-1.41)$ \\
\hline \multicolumn{5}{|l|}{ Occupational class } \\
\hline High professionals & $1.00(-)$ & $1.00(-)$ & $1.00(-)$ & $1.00(-)$ \\
\hline Other non-manual and manual workers & $1.03(0.74-1.43)$ & $1.12(0.92-1.36)$ & $1.06(0.84-1.32)$ & $1.12(0.87-1.43)$ \\
\hline Not working for pay & $1.46(1.05-2.02)$ & $1.45(1.19-1.75)$ & $1.36(1.10-1.70)$ & $1.20(0.93-1.54)$ \\
\hline
\end{tabular}




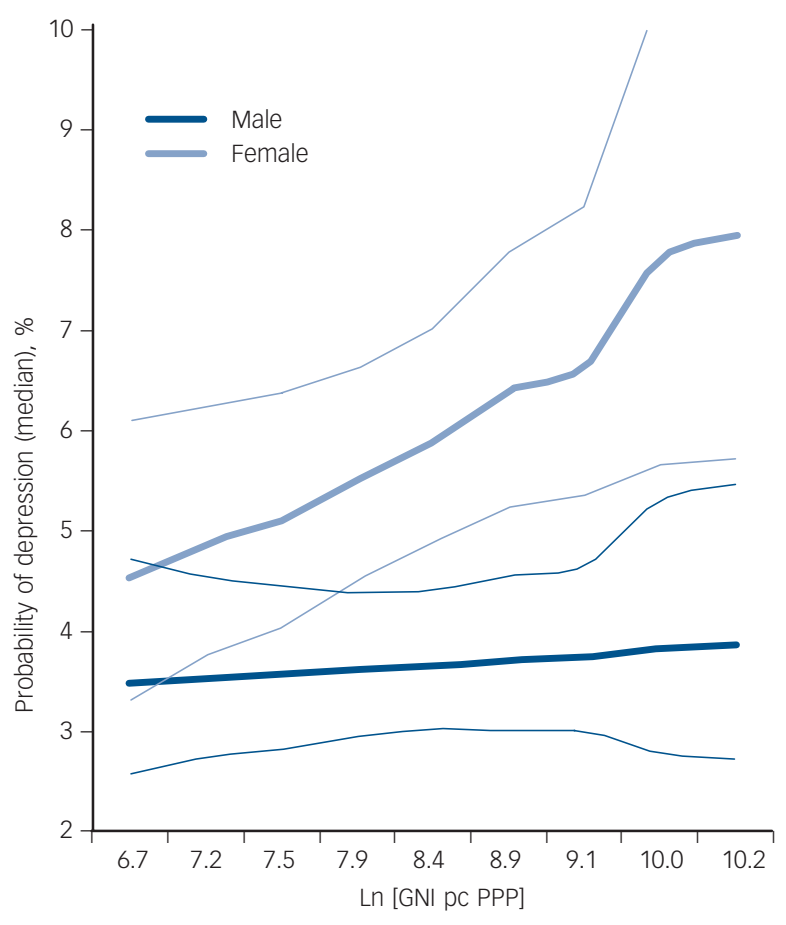

Fig. 2 Cross-level interaction between gender and gross national income (GNI) of countries.

PPP, purchasing power parity.

changing formulae for calculation, and varying thresholds for classifying countries between low-, middle- and high-HDI countries. ${ }^{36,37}$ As we discuss below, composite indicators may limit the understanding of the contributions of the independent variables comprising it, leading to possible misinterpretations.

A few other studies have also tested the income inequality hypothesis using individual-level data but in contextual units smaller than countries, with inconsistent results. Three studies ${ }^{8,9,12}$ found no evidence of a relationship between income inequality and mental ill health. One study found a small association between income inequality and depressive symptoms, with analysis only adjusted for age and gender. ${ }^{38}$ Two further studies found income inequality to be associated with poor mental

(a)

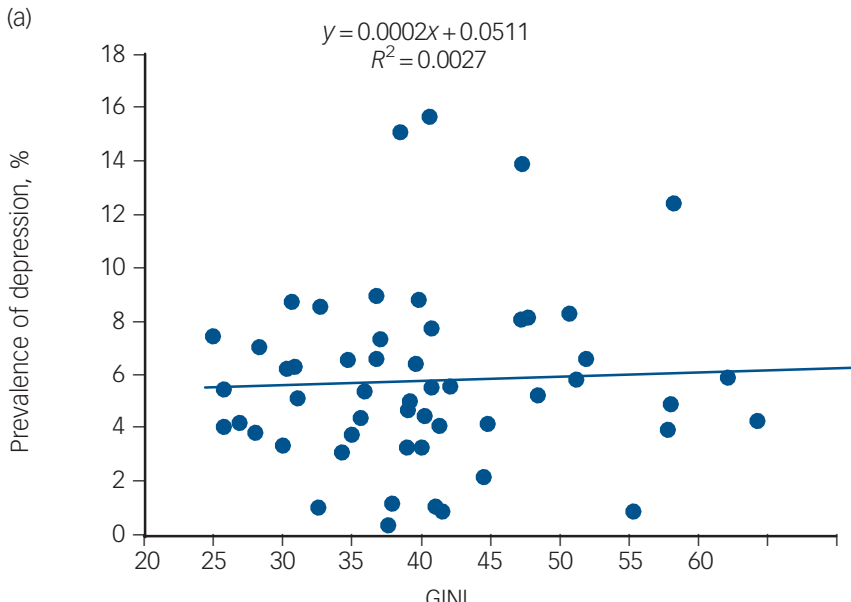

health outcomes but in (contrasting) subgroups: new mothers belonging to the low-income group in the first ${ }^{10}$ and among wealthier people in the other. ${ }^{39}$ Therefore, the evidence to support an association between income inequality and mental disorders, such as depression, is weak and inconsistent.

\section{Individual correlates of depression}

As consistently reported previously, ${ }^{3,6}$ we found female gender and being divorced, separated or widowed to be associated with depression. Notably, we found the risk of depression among women, but not men, to increase with increasing GNI of countries. Women in high-income countries may be more likely to acknowledge symptoms of depression. However, it may also be possible that changes in traditional gender roles or taking up multiple roles may actually lead to a narrowing between the rates of depression in women and men. ${ }^{40}$ Further research is required to clarify the reasons and mechanisms behind this finding.

Another common observation in the literature is that depression is more common in socially disadvantaged people. ${ }^{41}$ However, associations of depression with various individual-level socioeconomic indicators has yielded inconsistent results. ${ }^{15,16,41}$ Such inconsistencies have fuelled discussions that the various measures of socioeconomic status should not be used interchangeably, since they may convey distinct concepts, and have varying associations with mental health depending on the sociocultural setting. ${ }^{42-44}$ The relevance of specific socioeconomic measures in particular societies may also be context dependent for other reasons. For example, the lack of assets included in our material assets index may reflect personal choice rather than socioeconomic circumstances for many individuals in highincome countries.

It has also been discussed in detail previously how different mechanisms may be at play in the relationship between the various socioeconomic measures and depression. ${ }^{42}$ For instance, education may help to protect against depression by contributing to cognitive skills, attitudes and values shaping health-related behaviours; ${ }^{16,45}$ occupational class may measure prestige and power of individuals within society, and material assets may convey standard of living and access to services. ${ }^{42-44}$

In our attempt to isolate the effect of material assets and household spending on depression, we found that greater material assets were protective against depression in all analyses; but that greater household spending was either not associated (crude

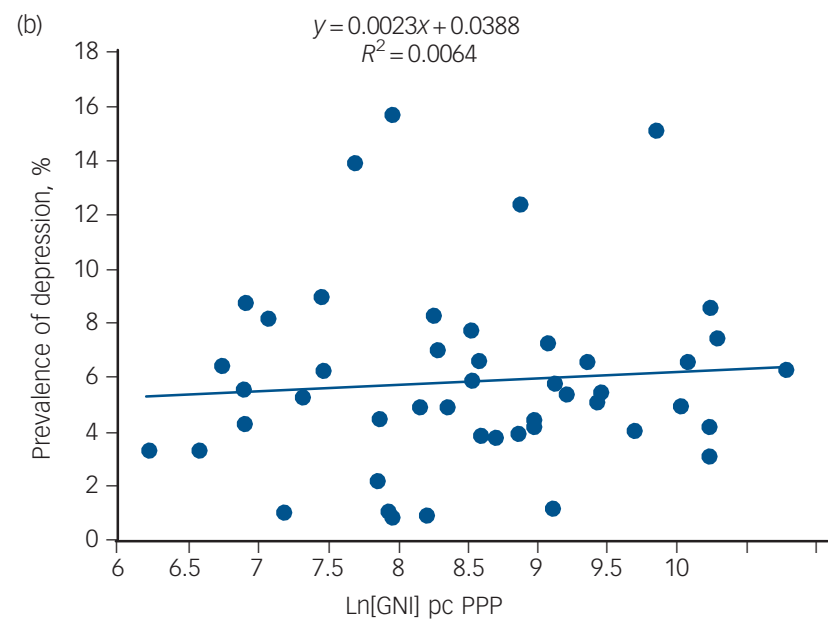

Fig. 3 The prevalence of depression by country-level measures of income inequalities and absolute income. 
analysis) or related to an increased odds of depression (adjusted analysis). Notably, both assets and spending are equated with 'income' or 'wealth', and often combined to produce summary variables of 'permanent income'. For instance, a paper using the WHS data reported that 'income' was inversely associated with depression ${ }^{17}$ using a composite measure of 'permanent income' derived by combining data on assets as well as expenditure among other variables. ${ }^{24}$ Our findings suggest that material possessions and living conditions, rather than spending, drive such reported associations. Our findings also demonstrate how the use of summary variables may impede the understanding of underlying phenomena behind such associations and may explain the inconsistencies in the findings of previous literature using varying measures of 'income.' 3,41

Nevertheless, the relationship between spending and depression in adjusted analysis is counterintuitive. Further analysis of this relationship revealed that people with the lowest education and assets who reported higher household spending were at the highest risk of depression, although tests for interactions were not statistically significant. One possibility is that such a relationship is mediated by incurred debt in people who spend more than they can afford. ${ }^{46}$ The data available were insufficient to test specific mechanisms, but future research could explore the relative contribution and direction of the relationship of these measures with depression.

\section{Strengths and limitations}

An important strength of this study is the large sample using a consistent methodology specifically designed for cross-national comparisons. Depression was identified using a validated questionnaire embedded in a face-to-face interview, and various individual-level socioeconomic measures were available. We used multilevel methods, which are the most appropriate design to account for any country-level clustering of observations, and simultaneously study contextual and individual determinants of depression. Despite the use of comparable methods across the countries, it is possible that people in different countries may conceptualise and answer survey questions differently and therefore measurement biases both in the prevalence estimates of depression and its determinants cannot be ruled out. ${ }^{28,29}$ Furthermore, since we could not use probability weights in the multilevel regression models in MLWin, our regression analysis was conducted using unweighted data. This strategy is unlikely to have had any significant effects on our ORs and we found almost identical results in sensitivity analyses using probability weights to look at associations between the individual-level variables and depression in a single-level analysis. Although we focused on income and income inequality data at a country level, other unknown contextual factors may contribute to the unexplained variance. Also, the higher level unit of country may be too large to study contextual effects, but researchers have argued otherwise. ${ }^{7}$ Finally, we did not have data on other intermediate levels such as households or neighbourhoods, so it is likely that their contribution towards the variance in depression is reflected in the individual-level estimates. It should be noted however, that the contribution of such intermediate levels in the variation of depression or common mental disorders has been relatively little $(<5 \%)$ in studies conducted in high-income countries. ${ }^{13,30-32}$

\section{Implications}

Individual-level factors appeared to explain most of the crossnational variation in the prevalence of depression but countrylevel factors also made a contribution. The importance of these contextual factors appeared to increase with decreasing economic development of countries. This finding needs further attention, and may have implications for the transferability of mental health promotion strategies from high- to low-income settings. Neither national income, nor income inequalities explained much of this variation, and our findings do not support the relativist hypothesis of country-level income inequalities to be a major determinant of depression. On the contrary, we found more support for material explanations of depression, through associations with individual-level material assets. Our findings of the divergent relationship of assets and spending with depression emphasise that different socioeconomic measures are not interchangeable in their associations with depression.

Dheeraj Rai, MBBS, MRCPsych, Academic Unit of Psychiatry, School of Social and Community Medicine, University of Bristol, UK; Pedro Zitko, MD, MSC, Academic Unit of Psychiatry, School of Social and Community Medicine, University of Bristol, UK, and Department of Epidemiology, Sub-secretariat of Public Health, Ministry of Health, Chile; Kelvyn Jones, PhD, Centre for Multilevel Modelling and School of Geographical Sciences, University of Bristol, UK. John Lynch $\mathrm{MPH}$, PhD, Discipline of Public Health, school of Population Heath and Clinical Practice, University of Adelaide, Australia, and School of Social and Community Medicine, University of Bristol, UK; Ricardo Araya, MRCPsych, PhD, Academic Unit of Psychiatry, School of Social and Community Medicine, University of Bristol, UK

Correspondence: Dheeraj Rai, Academic Unit of Psychiatry, School of Social and Community Medicine, University of Bristol, Oakfield House, Oakfield Grove, Clifton, Bristol BS8 2BN, UK. Email: dheeraj.rai@bristol.ac.uk

First received 25 Mar 2012, final revision 6 Nov 2012, accepted 10 Dec 2012

\section{Acknowledgements}

We thank the World Health Survey team at the World Health Organization for access to the data.

\section{References}

1 Moussavi S, Chatterji S, Verdes E, Tandon A, Patel V, Ustun B. Depression, chronic diseases, and decrements in health: results from the World Health Surveys. Lancet 2007; 370: 851-8.

2 Murray CJL, Lopez AD. The Global Burden of Disease. Harvard University Press, 2008.

3 Bromet E, Andrade LH, Hwang I, Sampson NA, Alonso J, de Girolamo G, et al. Cross-national epidemiology of DSM-IV major depressive episode. BMC Med 2011; 9: 90.

4 Simon GE, Goldberg DP, Von Korff M, Ustun TB. Understanding cross-national differences in depression prevalence. Psychol Med 2002; 32: 585-94.

5 Demyttenaere K, Bruffaerts R, Posada-Villa J, Gasquet I, Kovess V, Lepine JP, et al. Prevalence, severity, and unmet need for treatment of mental disorders in the World Health Organization World Mental Health Surveys JAMA 2004; 291: 2581-90

6 Weissman MM, Bland RC, Canino GJ, Faravelli C, Greenwald S, Hwu HG, et al. Cross-national epidemiology of major depression and bipolar disorder. JAMA 1996; 276: 293-9.

7 Pickett KE, Wilkinson RG. Inequality: an underacknowledged source of mental illness and distress. Br J Psychiatry 2010; 197: 426-8.

8 Gresenz CR, Sturm R, Tang L. Income and mental health: unraveling community and individual level relationships. J Ment Health Policy Econ 2001; 4: $197-203$.

9 Henderson C, Liu X, Diez Roux AV, Link BG, Hasin D. The effects of US state income inequality and alcohol policies on symptoms of depression and alcohol dependence. Soc Sci Med 2004; 58: 565-75.

10 Kahn RS, Wise PH, Kennedy BP, Kawachi I. State income inequality, household income, and maternal mental and physical health: cross sectional national survey. BMJ 2000; 321: 1311-5

11 Pickett KE, James OW, Wilkinson RG. Income inequality and the prevalence of mental illness: a preliminary international analysis. J Epidemiol Community Health 2006; 60: 646-7.

12 Sturm R, Gresenz CR. Relations of income inequality and family income to chronic medical conditions and mental health disorders: national survey. BMJ 2002; 324: 20-3. 
13 Weich S, Twigg L, Holt G, Lewis G, Jones K. Contextual risk factors for the common mental disorders in Britain: a multilevel investigation of the effects of place. J Epidemiol Community Health 2003; 57: 616-21.

14 Cifuentes M, Sembajwe G, Tak S, Gore R, Kriebel D, Punnett L. The association of major depressive episodes with income inequality and the human development index. Soc Sci Med 2008; 67: 529-39.

15 Laaksonen E, Martikainen P, Lahelma E, Lallukka T, Rahkonen O, Head J, et al. Socioeconomic circumstances and common mental disorders among Finnish and British public sector employees: evidence from the Helsinki Health Study and the Whitehall II Study. Int J Epidemiol 2007; 36: 776-86.

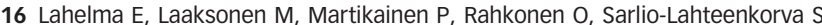
Multiple measures of socioeconomic circumstances and common mental disorders. Soc Sci Med 2006; 63: 1383-99.

17 Ayuso-Mateos JL, Nuevo R, Verdes E, Naidoo N, Chatterji S. From depressive symptoms to depressive disorders: the relevance of thresholds. Br J Psychiatry 2010; 196: 365-71.

18 Ustun TB, Chatterji S, Mechbal A, Murray CJL. The World Health Surveys. In Health Systems Performance Assessment: Debates, Methods and Empiricism (eds CJL Murray, DB Evans): 797-808. World Health Organization, 2003.

19 Kessler RC, Ustun TB. The World Mental Health (WMH) Survey Initiative version of the World Health Organization (WHO) Composite International Diagnostic Interview (CIDI). Int J Methods Psychiatr Res 2004; 13: 93-121.

20 World Health Organization. The ICD-10 Classification of Mental and Behavioural Disorders Diagnostic Criteria for Research. WHO, 1993.

21 Lequiller F, Blades D. Understanding National Accounts. OECD, 2006.

22 Lynch JW, Smith GD, Kaplan GA, House JS. Income inequality and mortality: importance to health of individual income, psychosocial environment, or material conditions. BMJ 2000; 320: 1200-4

23 Xu K, Ravndal F, Evans DB, Carrin G. Assessing the reliability of household expenditure data: results of the World Health Survey. Health Policy 2009; 91 297-305.

24 Ferguson B, Tandon A, Gakidou E, Murray C. Estimating permanent income using indicator variables. In Health Systems Performance Assessment: Debates, Methods and Empiricism (eds CJL Murray, DB Evans): 747-60. World Health Organization, 2003.

25 Rasbash J, Steele F, Browne WJ, Goldstein H. A User's Guide to MLwiN, v2.10. 2009. Centre for Multilevel Modelling, University of Bristol.

26 Merlo J, Chaix B, Ohlsson $H$, Beckman A, Johnell $K$, Hjerpe $P$, et al. A brief conceptual tutorial of multilevel analysis in social epidemiology: using measures of clustering in multilevel logistic regression to investigate contextual phenomena. J Epidemiol Community Health 2006; 60: 290-7.

27 Goldstein H, Rasbash J. Improved approximations for multilevel models with binary responses. J R Stat Soc Ser A Stat Soc 1996; 159: 505-13.

28 Cross-national comparisons of the prevalences and correlates of mental disorders. WHO International Consortium in Psychiatric Epidemiology. Bull World Health Organ 2000; 78: 413-26.

29 Phillips MR, Zhang J, Shi Q, Song Z, Ding Z, Pang S, et al. Prevalence, treatment, and associated disability of mental disorders in four provinces in China during 2001-05: an epidemiological survey. Lancet 2009; 373 2041-53.

30 Araya R, Dunstan F, Playle R, Thomas H, Palmer S, Lewis G. Perceptions of social capital and the built environment and mental health. Soc Sci Med 2006; 62: 3072-83.

31 Thomas $\mathrm{H}$, Weaver $\mathrm{N}$, Patterson J, Jones $\mathrm{P}$, Bell T, Playle R, et al. Mental health and quality of residential environment. Br J Psychiatry 2007; 191: 500-5.

32 Weich S, Holt G, Twigg L, Jones K, Lewis G. Geographic variation in the prevalence of common mental disorders in Britain: a multilevel investigation. Am J Epidemiol 2003; 157: 730-7.

33 Wilkinson RG, Pickett KE. The problems of relative deprivation: why some societies do better than others. Soc Sci Med 2007; 65: 1965-78.

34 Subramanian SV, Jones K, Kaddour A, Krieger N. Revisiting Robinson: the perils of individualistic and ecologic fallacy. Int J Epidemiol 2009; 38: 342-60.

35 Lynch J, Smith GD, Hillemeier M, Shaw M, Raghunathan T, Kaplan G. Income inequality, the psychosocial environment, and health: comparisons of wealthy nations. Lancet 2001; 358: 194-200.

36 McGillivray M. The Human-Development Index - yet another redundant composite development indicator. World Development 1991; 19: 1461-8.

37 Wolff $\mathrm{H}$, Chong $\mathrm{H}$, Auffhammer M. Classification, detection and consequences of data error: evidence from the Human Development Index. Econ J 2011; 121: 843-70.

38 Fiscella K, Franks P. Individual income, income inequality, health, and mortality: what are the relationships? Health Serv Res 2000; 35: 307-18.

39 Weich S, Lewis G, Jenkins SP. Income inequality and the prevalence of common mental disorders in Britain. Br J Psychiatry 2001; 178: 222-7.

40 Seedat S, Scott KM, Angermeyer MC, Berglund P, Bromet EJ, Brugha TS, et al. Cross-national associations between gender and mental disorders in the World Health Organization World Mental Health Surveys. Arch Gen Psychiatry 2009; 66: 785-95.

41 Lorant V, Deliege $\mathrm{D}$, Eaton W, Robert A, Philippot P, Ansseau M Socioeconomic inequalities in depression: a meta-analysis. Am J Epidemio 2003; 157: 98-112.

42 Araya R, Lewis G, Rojas G, Fritsch R. Education and income: which is more important for mental health? J Epidemiol Community Health 2003; 57: 501-5.

43 Galobardes B, Shaw M, Lawlor DA, Lynch JW, Davey SG. Indicators of socioeconomic position (part 1). J Epidemiol Community Health 2006; 60 7-12.

44 Krieger N, Williams DR, Moss NE. Measuring social class in US public health research: concepts, methodologies, and guidelines. Annu Rev Public Health 1997; 18: 341-78.

45 Patel V, Kleinman A. Poverty and common mental disorders in developing countries. Bull World Health Organ 2003; 81: 609-15.

46 Zimmerman FJ, Bell JF. Income inequality and physical and mental health: testing associations consistent with proposed causal pathways. J Epidemio Community Health 2006; 60: 513-21. 